This item was submitted to Loughborough's Research Repository by the author.

Items in Figshare are protected by copyright, with all rights reserved, unless otherwise indicated.

\title{
A combined approach of differential scanning calorimetry and hot-stage microscopy with image analysis in the investigation of sulfathiazole polymorphism
}

\section{PLEASE CITE THE PUBLISHED VERSION}

http://dx.doi.org/10.1007/s10973-009-0001-z

\section{PUBLISHER}

(c) Akademiai Kiado / Springer

\section{VERSION}

AM (Accepted Manuscript)

\section{LICENCE}

CC BY-NC-ND 4.0

\section{REPOSITORY RECORD}

Abu Bakar, Mohd R., Zoltan K. Nagy, and Chris D. Rielly. 2013. "A Combined Approach of Differential Scanning Calorimetry and Hot-stage Microscopy with Image Analysis in the Investigation of Sulfathiazole Polymorphism". figshare. https://hdl.handle.net/2134/11461. 
This item was submitted to Loughborough's Institutional Repository (https://dspace.lboro.ac.uk/) by the author and is made available under the following Creative Commons Licence conditions.

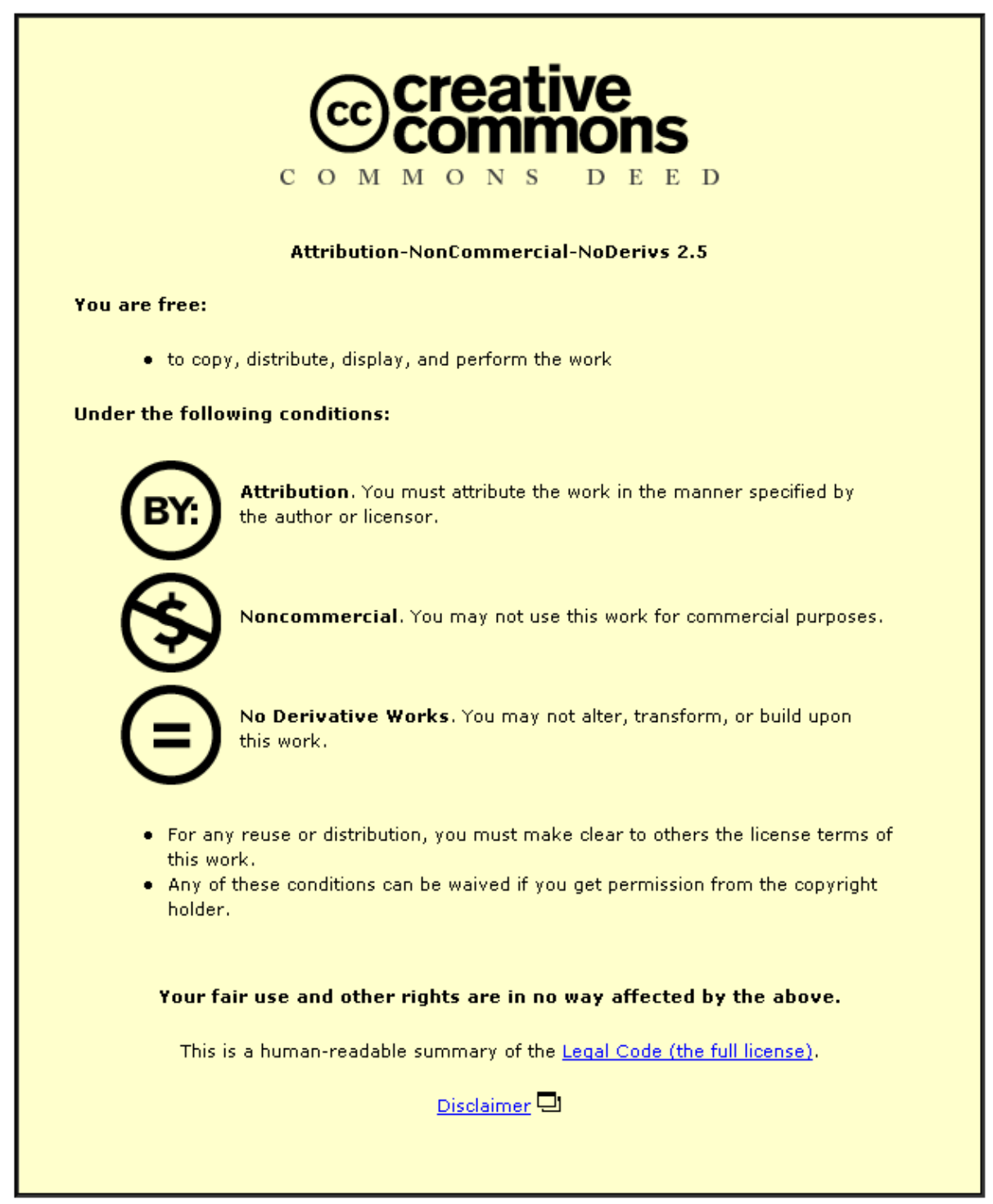

For the full text of this licence, please go to: http://creativecommons.org/licenses/by-nc-nd/2.5/ 


\title{
A COMBINED APPROACH OF DIFFERENTIAL SCANNING CALORIMETRY AND HOT-STAGE MICROSCOPY WITH IMAGE ANALYSIS IN THE INVESTIGATION OF SULFATHIAZOLE POLYMORPHISM
}

\author{
Kingdom \\ *Corresponding author \\ Tel.: +44 1509 222516; Fax: +44 1509223923 \\ E-mail address: Z.K.Nagy@lboro.ac.uk
}

Mohd Rushdi Abu Bakar, Zoltan Kalman Nagy*, Christopher David Rielly

Department of Chemical Engineering, Loughborough University, Loughborough, Leicestershire, LE11 3TU, United

\begin{abstract}
A combination of differential scanning calorimetry and hot-stage microscopy with image analysis has been used to investigate the polymorphism of sulfathiazole. The use of light intensity profiles obtained from the HSM images, as an alternative way to present results of the HSM analysis, was found to be useful in describing and verifying thermal events. The approach provides a unique insight into the polymorphic transformations and thermal behaviour exhibited by this compound. The results of the experiments show that sulfathiazole tends to crystallise as mixtures of polymorphs, even though the literature methods for producing pure polymorph were followed.
\end{abstract}

Keywords: DSC; HSM; image processing; polymorphic transformation.

\section{Introduction}

Crystallisations of active pharmaceutical ingredients (APIs) particularly those that possess multiple polymorphic forms are amongst the most critical, yet least understood pharmaceutical processes. Statistically, about $85 \%$ of APIs exhibit polymorphism and $50 \%$ have multiple polymorphic forms [1]. The polymorphs of a crystal can exhibit a variety of structures, which have different inter- and intra-molecular interactions. Thus, they have different free energies and consequently different physico-chemical properties and mechanical behaviours [2]. These have an impact on downstream process operations, such as isolation, filtering and drying, and can affect the therapeutic properties of the final product. For this reason, an extensive characterisation of all known solid forms of the API is necessary in order to understand and differentiate them properly. Solid state characterisation has become an integral part of the drug development process and its importance has been recognised from scientific as well as regulatory concerns. It has been used to provide information about the therapeutic properties of the polymorphs of a drug substance such as their bioavailability, rate of dissolution and stability. It also has been used to assess the success of the crystallisation control approach in producing certain polymorphs $[3,4]$. In addition, the obtained knowledge on the solid state properties of the API could assist in generating a valuable protection of intellectual property e.g. through a patent [2]. 
Thermal analysis is one of the established solid state characterization techniques. Its application to characterise pharmaceutical products has been extensively reviewed in the literature [5-9]. One of the most widely used thermal analysis techniques for the investigation of polymorphism is differential scanning calorimetry (DSC). The technique basically involves the application of a heating/cooling signal to a sample and the subsequent measurement of the temperature and enthalpy changes associated with thermal events such as melting and polymorphic transformation [10]. The popularity of DSC is due to its simplicity and rapidity of measurement, requirement for a small sample size and ability to provide detailed information about the physical and energetic properties of a sample [11].

Another thermal analysis technique for the investigation of polymorphism is hot-stage microscopy (HSM). The technique combines microscopy and thermal analysis, and allows visual observation of the behaviour of a sample through a microscope during heating or cooling [12]. This visual technique easily distinguishes a polymorphic transformation from the melting process [13]; hence HSM is very useful to provide information for the confirmation of the thermal events that are observed using other techniques. Some examples of the application of HSM in the thermal analysis of pharmaceuticals have been comprehensively presented by Vitez and Newman [14]. Recent technological advances have expanded the capabilities of the visual techniques, for example with the use of software, which not only captures the image, but also performs an image analysis, for example by computing the total light intensity. The latter may be calculated as the sum or average of the grey levels in all pixel (pixel value ranges from black $=0$ to white $=255$ ). As the image becomes brighter, the light intensity value becomes higher. The application of image analysis to evaluate HSM results is very attractive because of its ability to translate visual effects, which other techniques may not be able to provide, into quantitative information. The introduction of an alternative way of presenting HSM results may broaden the application of HSM since it is conventionally used to confirm results of other thermal analysis techniques only. Some visual techniques, including optical microscopy, non-invasive video imaging systems and Lasentec's inprocess video microscopy, have successfully utilized image analysis in the investigation of the dynamics of product quality, such as size and shape of particulates in real-time and in situ [15-17]. However, based on authors' knowledge, the use of image analysis to evaluate HSM results has never been reported.

Although solid state properties of different polymorphs of a compound may be different, very often, they are only marginally different. For this reason, it is essential to differentiate them using a variety of characterisation techniques to avoid making erroneous conclusions. In addition, the interpretation of an individual characterisation technique always requires support from other techniques. A 
reliable combined technique that can quickly differentiate between different polymorphs and determine if a solid contains a pure polymorph or a mixture of polymorphs would be preferable. Combined or coupled thermal analysis techniques were found to provide quicker ways for interpretation of polymorphic phenomena, while at the same time, the sensitivity, the reliability and the robustness of the results remain of high quality $[18,19]$. This is illustrated by a coupling of DSC and HSM, which have proved to be very successful in the study of phase diagrams and polymorphic transformation [20-23]. Based on their works, visual observation through HSM was found to be a more sensitive indicator of phase changes than the DSC measurements alone; the changes happening on the surface of the crystals could clearly be seen using HSM even when the DSC showed no thermal event [21].

Sulfathiazole has been chosen as the model system in this study. At present, it has five known polymorphs that are well characterised and clearly described in the literature [24-26]. Although the polymorphism of sulfathiazole has been extensively and repeatedly investigated by various researchers [27-30], it remains difficult to produce a pure polymorph; most of the time, the desired polymorph contains impurities from at least one other form [31-34].

In this paper, examples are presented of complementary application of DSC and HSM with image analysis in the investigation of sulfathiazole polymorphism. The image analysis tool used in this work allows the selection of regions of interest and restricts image analysis to each selected region only. The aim of this work is two-fold: (i) to give a contribution to the methods of investigating polymorphism through a combined approach of DSC-HSM with image analysis, and (ii) to gain more understanding on the polymorphism of sulfathiazole.

\section{Methods and Materials}

\subsection{Materials.}

Sulfathiazole was purchased from Sigma-Aldrich with a purity of $98 \%$. The solvents used are deionised water, 1-propanol, acetone and chloroform. Except water, all other solvents were analytical reagent grade purchased from Fisher Scientific.

\subsection{Crystallisation of the polymorphs.}

Different polymorphs were generated using methods available in the literature [28, 32] as shown in Table 1. It is known that there are some inconsistencies in the enumeration of the sulfathiazole polymorphs in the literature [24, 35]. In this work, the enumeration of the polymorphs follows the convention proposed by Anwar and Chan and their co-researchers [25, 28]. In order to further 
clarify the identity of the polymorphs, the Cambridge Structural Database (CSD) reference codes are quoted in the bracket.

Table 1. Preparation methods to produce different polymorphs of sulfathiazole.

\begin{tabular}{|c|c|c|}
\hline $\begin{array}{l}\text { Method } \\
\text { no. }\end{array}$ & $\begin{array}{l}\text { Polymorph to be } \\
\text { produced }\end{array}$ & Procedure \\
\hline 1 & I (SUTHAZ01) & $\begin{array}{l}\text { Heating } 0.5 \mathrm{~g} \text { of sulfathiazole in } 50 \mathrm{ml} \text { of } 1 \text {-propanol in a flask on a hot } \\
\text { plate to dissolution, followed by natural cooling at } 25^{\circ} \mathrm{C} \text {. }\end{array}$ \\
\hline 2 & II (SUTHAZ05) & $\begin{array}{l}\text { Rapid cooling of a saturated aqueous solution of sulfathiazole at } 60^{\circ} \mathrm{C} \\
(0.5 \mathrm{~g} \text { in } 100 \mathrm{ml} \text { water }) \text { from } 80^{\circ} \mathrm{C} \text { to } 4^{\circ} \mathrm{C} \text { at a set rate of } 10^{\circ} \mathrm{C} \mathrm{min}^{-1} \text { in a } \\
\text { crystalliser. }\end{array}$ \\
\hline 3 & III (SUTHAZ05) & $\begin{array}{l}\text { Slow cooling of a saturated aqueous solution of sulfathiazole }(0.5 \mathrm{~g} \text { in } \\
100 \mathrm{ml} \text { water) at a rate of } 0.1^{\circ} \mathrm{C} \mathrm{min}{ }^{-1} \text { from } 80^{\circ} \mathrm{C} \text { to } 20^{\circ} \mathrm{C} \text { in a } \\
\text { crystalliser. }\end{array}$ \\
\hline 4 & IV (SUTHAZ) & $\begin{array}{l}\text { Natural cooling to } 20^{\circ} \mathrm{C} \text { a saturated solution of sulfathiazole in a } 50: 50 \\
\text { mixture of acetone: chloroform at } 50^{\circ} \mathrm{C}(1.3 \mathrm{~g} \text { in } 100 \mathrm{ml}) \text {. }\end{array}$ \\
\hline 5 & V (SUTHAZ04) & $\begin{array}{l}\text { Boiling to evaporate a saturated aqueous solution of sulfathiazole at } \\
60^{\circ} \mathrm{C}(0.8 \mathrm{~g} \text { in } 50 \mathrm{ml} \text { water }) \text { in a beaker on a hot plate until almost dry. }\end{array}$ \\
\hline
\end{tabular}

All of the crystallised solids were vacuum filtered and subsequently, those crystals obtained from water, were immediately dried in a hot air oven at $105^{\circ} \mathrm{C}$ for 15 minutes, whereas crystals obtained from other solvents were dried in a desiccator.

2.3 Thermal analysis of polymorphs.

DSC - The thermal behaviour of the polymorphs was examined using a TA Instruments DSC Q10. About $8 \mathrm{mg}$ of sample was weigh into an aluminium pan and sealed hermetically. Analysis was carried out by heating the sample from 100 to $240^{\circ} \mathrm{C}$ at heating rates of 2,10 and $20^{\circ} \mathrm{C} \mathrm{min}^{-1}$ under constant purging of nitrogen at $40 \mathrm{~mL} \mathrm{~min}{ }^{-1}$. An empty aluminium pan was used as a reference in all the runs. Results were analysed using TA Instruments Universal Analysis 2000.

HSM - The thermal behaviour of the polymorphs was visually examined using a Mettler Toledo FP90 hot-stage system and a Leica DMLM microscope from 100 to $250^{\circ} \mathrm{C}$ at a heating rate of $10^{\circ} \mathrm{C}$ $\min ^{-1}$. Microscopic observations during experiments were displayed on a computer screen and recorded using a JVC colour video camera.

\subsection{HSM image analysis.}

MATLAB image processing toolbox (Matworks, Inc.) was used to compute mean values of light intensity of greyscale images in the HSM video clips. The computation was based on the average of grey levels in all pixel (pixel value ranges from black $=0$ to white $=255$ ). An algorithm for the computation is presented as a flowchart in Figure 1. In this paper, the mean light intensity values of the HSM greyscale images is presented as percentage HSM light intensity, defined as a percentage of an average greyscale intensity value divided by the largest value of average greyscale intensity. 


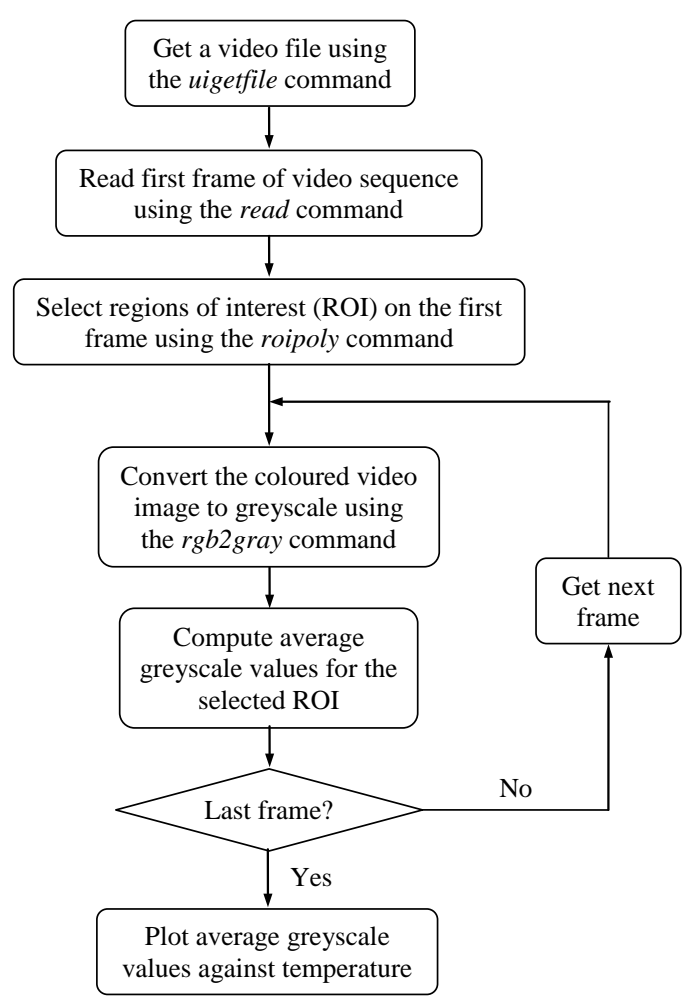

Figure 1. An algorithm for the computation of mean light intensity values of greyscale images in the HSM video clips.

\section{Results and Discussion}

\subsection{Crystals obtained by method 1 .}

The DSC thermograms of the crystals obtained by method 1 at various heating rates are presented in Figure 2. The onset of the first peak was observed between $121^{\circ} \mathrm{C}$ to $131^{\circ} \mathrm{C}$, with the peak maxima increased from $124^{\circ} \mathrm{C}$ to $136^{\circ} \mathrm{C}$, with increasing heating rates. The shifting of the onset of the peak and the peak maximum to higher temperatures as the heating rate increases is due to the effect of "thermal lag” within the system. The effect comes about as the result of the thermal lag between the DSC's furnace and the bottom of the sample pan, and/or the lag between the bottom of the sample pan and the sample, and/or the lag throughout the sample [36]. Therefore, although the use of a higher heating rate will reduce the experimental time, the thermal lag may affect the accuracy of the results. It can also be observed from Figure 2 that the baseline of the curves is increasingly offset with an increase in the heating rate. The height and width of the peak are also increased, which consequently increased the detection limit, but reduced the resolution as demonstrated by the appearance of an unresolved peak for the run at a heating rate of $20^{\circ} \mathrm{C} \mathrm{min}^{-1}$, whereas for the run at a heating rate of $2^{\circ} \mathrm{C} \mathrm{min}^{-1}$, the peak is undetected. In order to compromise with all these effects, a heating rate of $10^{\circ} \mathrm{C} \mathrm{m^{-1 }}$ was chosen for the subsequent thermal analysis experiments. 


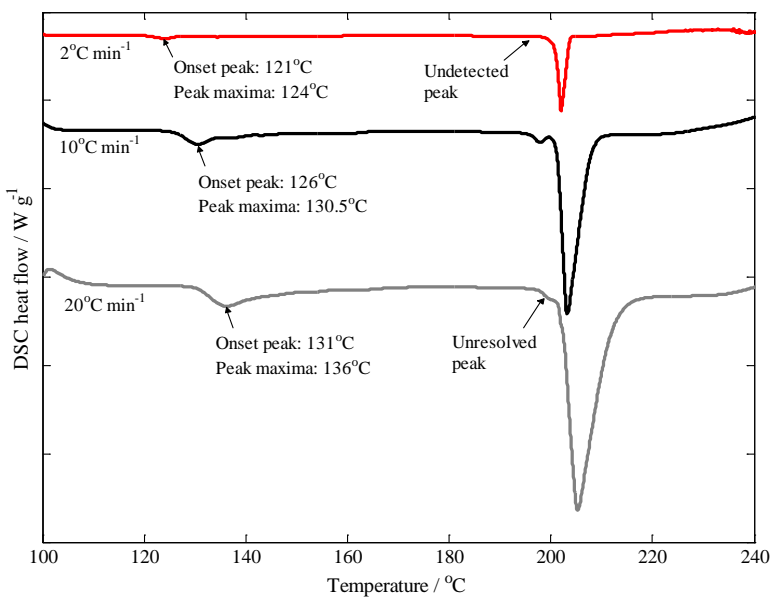

Figure 2. DSC thermograms of sulfathiazole crystals obtained by method 1 at various heating rates.

Figure 3 shows the DSC thermogram and the HSM light intensity of the crystals, while Figure 4 shows the snapshots of selected crystals during HSM analysis. Both experiments, DSC and HSM, were conducted at a heating rate of $10^{\circ} \mathrm{C} \mathrm{min}{ }^{-1}$. Based on the DSC thermogram in Figure 3, it can be seen that there are three major peaks. The peak with a maximum at $203.2^{\circ} \mathrm{C}$ corresponds to the melting peak of form I, while the peak at a maximum of $197.9^{\circ} \mathrm{C}$ corresponds to the melting peak of form II. Form I and form II are enantiotropically related, in which form I is stable from its melting point of $202^{\circ} \mathrm{C}$ down to $116.5^{\circ} \mathrm{C}$, while form II is a stable form below $116.5^{\circ} \mathrm{C}$ [37]. Some crystals of form I may have transformed into form II at room temperature during storage and when they were heated in the DSC experiment, some of them transformed back into form I. The formation of the peak at the maximum of $130.5^{\circ} \mathrm{C}$ may correspond to a polymorphic transformation from form II to form I. The thermal lag effect mentioned earlier may have contributed to the difference between the obtained transition temperature at $130.5^{\circ} \mathrm{C}$ and that from the literature at $116.5^{\circ} \mathrm{C}$ [37]. These events, which were implied by the results of the DSC analysis, were verified by the HSM analysis. HSM shows no melting at the expected polymorphic transformation peak at $130.5^{\circ} \mathrm{C}$, but it shows an optical property change, as can be observed by the difference between the highlighted crystals in (a) and (b) in Figure 4. The change reduced the brightness and thus the light intensity of the crystals as indicated in Figure 3 by the reduction in the HSM light intensity from $130.5^{\circ} \mathrm{C}$ onwards. The same visual observation through a HSM had been reported in the case of lithium sulphate salt in which a transformation of one of its polymorphs to another was accompanied by a striking change in birefringence [38]. Melting of form II was indicated by a small increase in the value of the light intensity, while melting of form I was shown by the continuous increase in the value of the light intensity as all the crystals have melted. Figure 4 shows the melting of form II and form I in (c) and (d), respectively. 


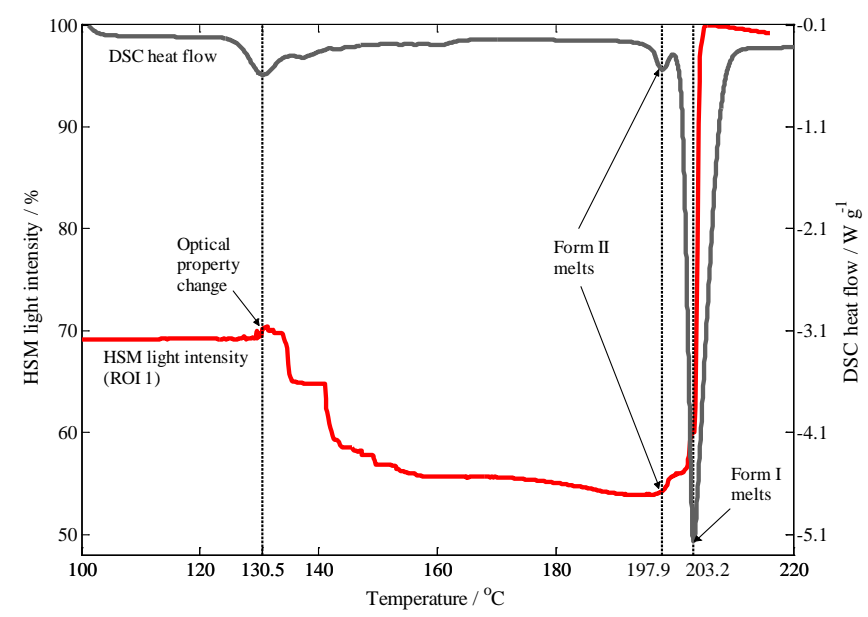

Figure 3. DSC thermogram and HSM light intensity of sulfathiazole crystals obtained by method 1 .
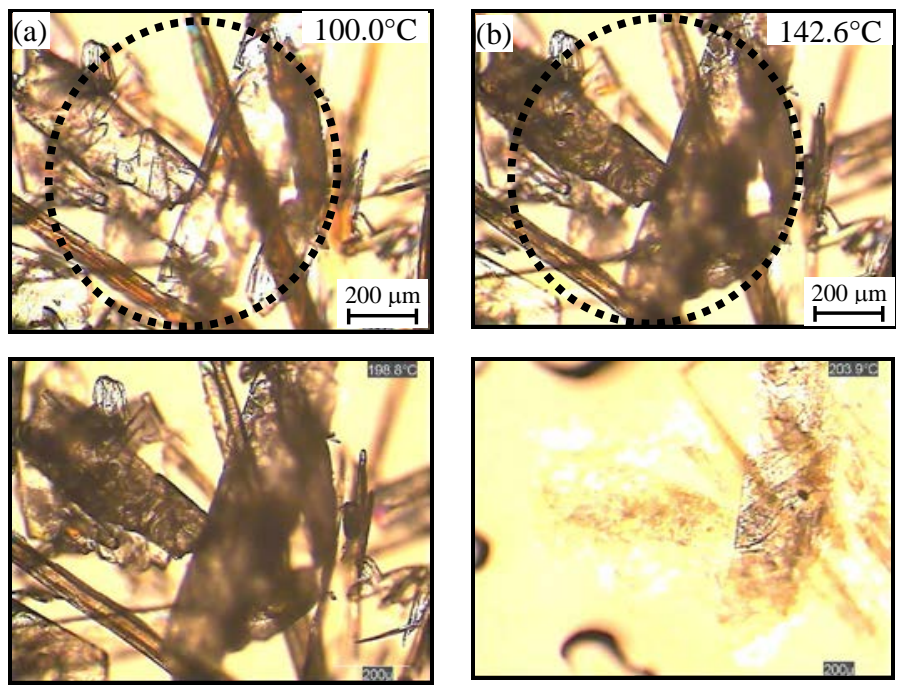

$\mathrm{F}_{\text {(C) }}^{(\mathrm{c})}$ ure 4. Images $198.8^{\circ} \mathrm{C}$ fatt(d) zole crystals $0_{0}^{203.9^{\circ} \mathrm{C}}$ by method 1 during HSM analysis taken at (a) $100.0^{\circ} \mathrm{C}$; (b) $142.14 .6^{\circ} \mathrm{C}$; (c)<smiles>C1CCCCCC1</smiles><smiles>C1CCC2(CC1)CCCC2</smiles>

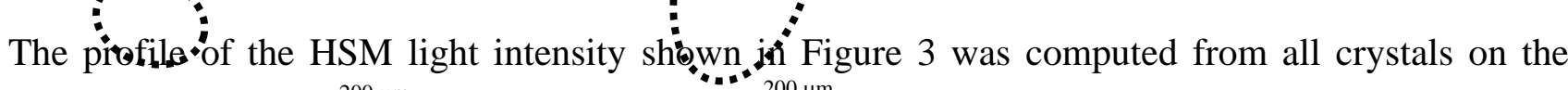
frame (ROI 1), whicl $\stackrel{200 \mu \mathrm{m}}{10}$ idrly comparable to the pruile of the sample's DSC thermogram. In order to investigate the capability and sensitivity of the HSM light intensity in describing thermal events of individual crystals, two ROI were selected; one was selected around a crystal that melts at $197.9^{\circ} \mathrm{C}$ (ROI 2) and another around a crystal that melts at $203.2^{\circ} \mathrm{C}$ (ROI 3), as highlighted in (c) and (d) in Figure 4, respectively. The computed profiles of light intensity are shown in Figure 5. It can be seen that all profiles indicate an optical property change with a decrease in the light intensity from $130.5^{\circ} \mathrm{C}$ onwards. The profile of ROI 3, however, shows a larger decrease in the light intensity compared to the profile of ROI 2, but this is believed to be due to the difference in the appearance of the images since ROI 2 is more blurred than ROI 3. The absolute changes in the HSM light intensity depend on the fraction of ROI pixels that are filled with the crystal. The ROI 2 and ROI 3 profiles show the melting of crystals at $197.9^{\circ} \mathrm{C}$ and $203.2^{\circ} \mathrm{C}$, respectively, with a sharp increase in the light intensity. The ROI 3 profile also shows a small peak that corresponds to the melting of a crystal in 
ROI 2, which demonstrates the sensitivity of the HSM light intensity to the changes happening on the surface of the crystals due to the melting of adjacent crystals. The results of DSC and HSM with image analysis show that the sulfathiazole crystals obtained by method 1 contain a mixture of form I and form II.

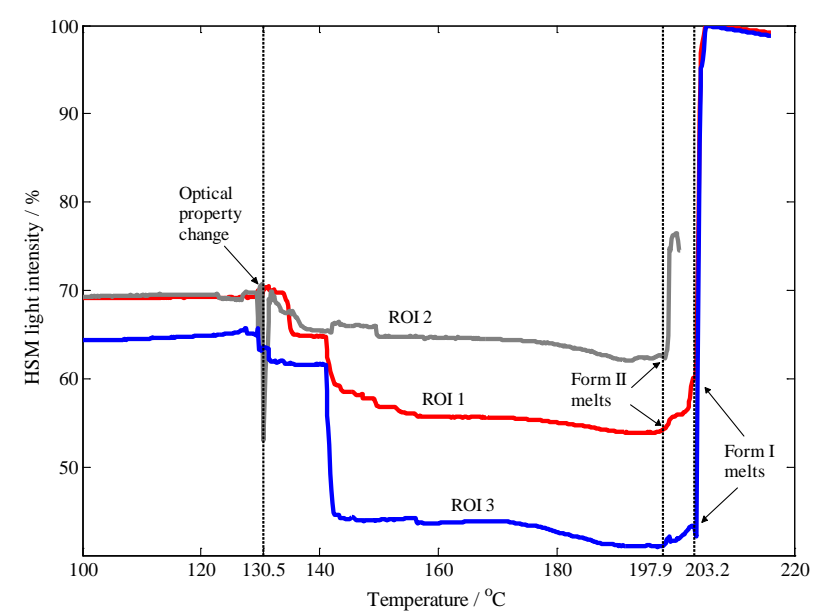

Figure 5. HSM light intensity profiles of sulfathiazole crystals obtained by method 1 at three different ROIs; all crystals on the frame (ROI 1); a crystal that melts at $197.9^{\circ} \mathrm{C}$ (ROI 2) and a crystal that melts at $203.2^{\circ} \mathrm{C}$ (ROI 3).

\subsection{Crystals obtained by method 2 .}

Figure 6 shows the profiles of the DSC thermogram and the HSM light intensity of the crystals produced by method 2. Figure 7 shows the snapshots of the crystals during HSM analysis. Based on Figure 6, the DSC thermogram indicates the presence of three major endotherm peaks. The first peak at a maximum of $168.5^{\circ} \mathrm{C}$ was not a melting peak as verified by the HSM analysis. The peak resulted from a change in the optical properties of the crystals, as shown by the difference in the appearance of the highlighted crystals between (a) and (b) in Figure 7. The phenomenon was indicated by fluctuation in the HSM light intensity profile between $159.3^{\circ} \mathrm{C}$ to a temperature slightly above $168.5^{\circ} \mathrm{C}$ and it was probably due to a transformation of form III to form I, since the transformation was reported to occur in a temperature range of 150 to $170^{\circ} \mathrm{C}$ [28]. The second peak at a maximum of $197.2^{\circ} \mathrm{C}$ on the DSC thermogram corresponds to a melting peak of form II, whilst the third peak at a maximum of $202.5^{\circ} \mathrm{C}$ corresponds to a melting peak of form I. The melting of form II and form I were verified by HSM analysis as shown in Figure 7 (d) and (e), respectively, and the subsequent increase in the HSM light intensity value at the corresponding melting temperatures in Figure 6. The HSM analysis was able to detect melting of form III as shown in Figure 7(c) and as indicated in Figure 6 by a small increase in the HSM light intensity value at $174.5^{\circ} \mathrm{C}$. This melting of form III was barely detected by the DSC. According to a report [29], a single melting peak of form II at its melting temperature can only be obtained if the crystals were purely form II. If only 
the slightest amount of form I present, form I will crystallise during the melting process of form II [29]. This indicates that the crystals obtained are actually a mixture of form I, form II and form III.

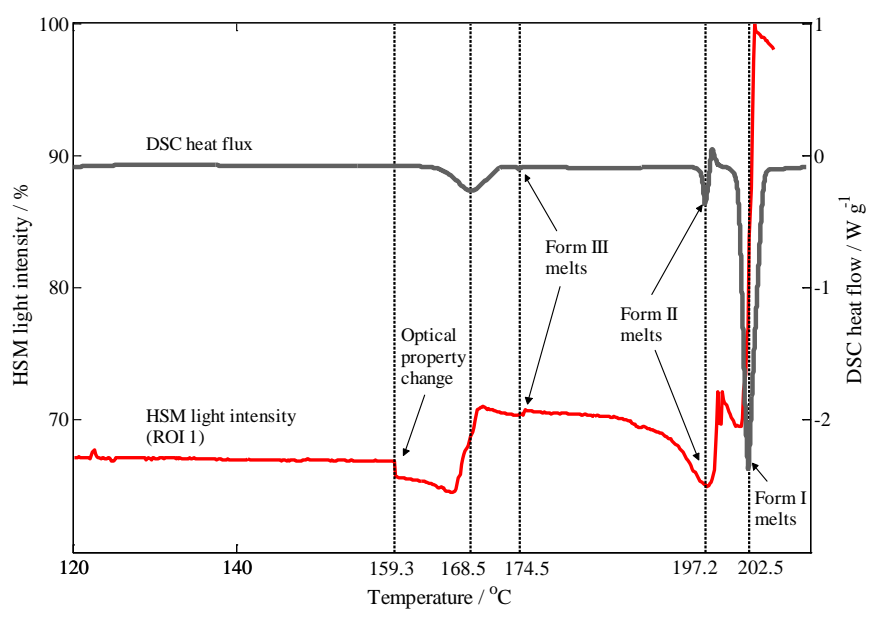

Figure 6. DSC thermogram and HSM light intensity of sulfathiazole crystals obtained by method 2.
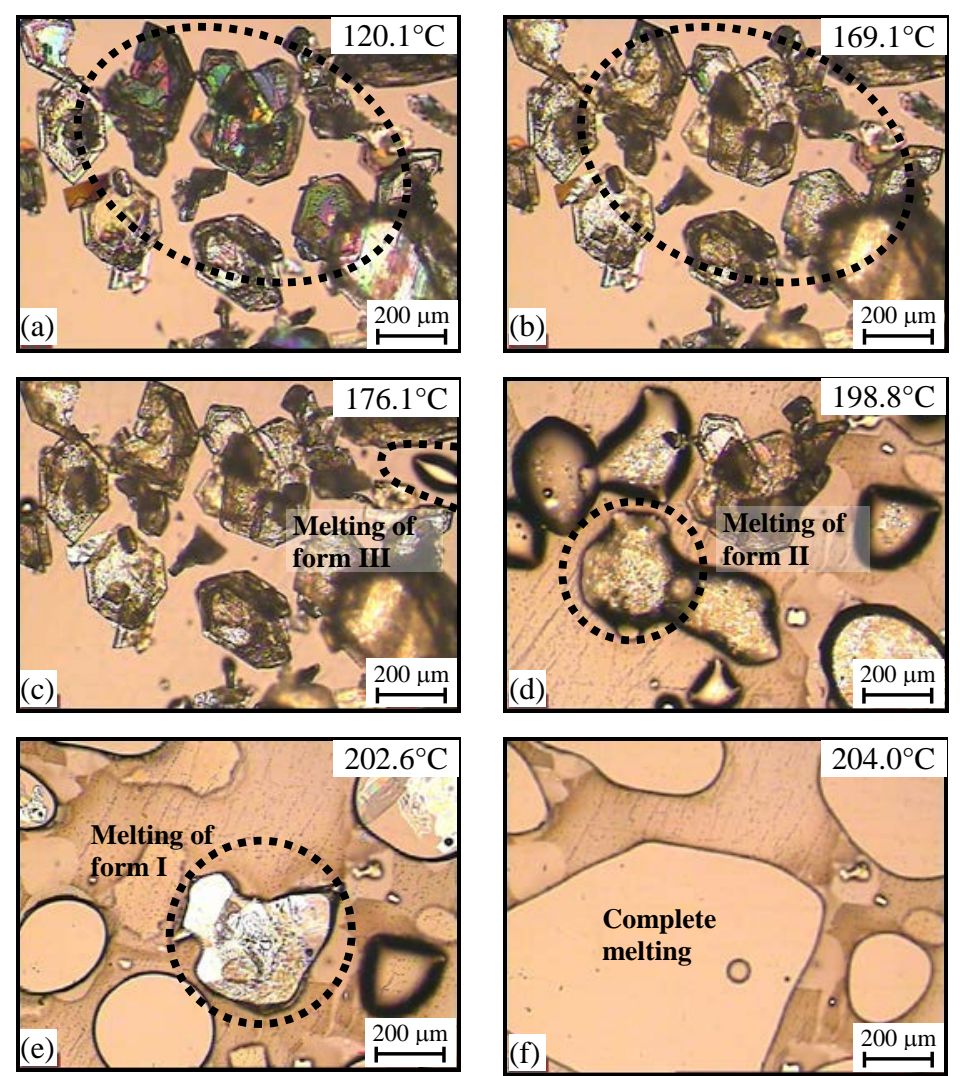

Figure 7. Images of sulfathiazole crystals obtained by method 2 during HSM analysis taken at (a) $120.1^{\circ} \mathrm{C}$; (b) $169.1^{\circ} \mathrm{C}$; (c) $176.1^{\circ} \mathrm{C}$; (d) $198.8^{\circ} \mathrm{C}$; (e) $202.6^{\circ} \mathrm{C}$ and (f) $204.0^{\circ} \mathrm{C}$.

The HSM light intensity profiles for various ROI were presented in Figure 8. ROI 2 was selected to represent a crystal that melts at $174.5^{\circ} \mathrm{C}$ as highlighted in Figure $7(\mathrm{c})$, ROI 3 represents crystals that melt at $197.2^{\circ} \mathrm{C}$ as shown in Figure $7(\mathrm{~d})$ and ROI 4 represents a crystal that melts at $202.5^{\circ} \mathrm{C}$ as shown in Figure 7(e). All profiles show a sharp increase in the light intensity at the corresponding melting temperatures of their represented crystals. Although there are some discrepancies between 
the value of temperatures to represent melting at inflection points shown by the HSM light intensity and the DSC heat flux peak maximum, the relative errors are very small, i.e. between 0.1 to $0.7 \%$. The fluctuation of the HSM light intensity profile between $159.3^{\circ} \mathrm{C}$ to $169.4^{\circ} \mathrm{C}$ that corresponds to the change in the optical properties of the crystals was shown by ROI 3 and ROI 4, but it was not shown by ROI 2. This result confirms that the phenomenon shown by the crystal in ROI 4 between $159.3^{\circ} \mathrm{C}$ to $169.4^{\circ} \mathrm{C}$ was due to a transformation of form III to form I. A similar phenomenon displayed by a crystal in ROI 2, on the other hand, was probably just due to a surface property change, since the crystal should not undergo a polymorphic transformation as it melted at its melting temperature of $197.2^{\circ} \mathrm{C}$ (corresponding to melting temperature of form II crystals). Nevertheless, the HSM light intensity profiles of individual crystals in this case have been demonstrated to help in confirming the presence of form I, form II and form III in the crystals obtained by method 2 .

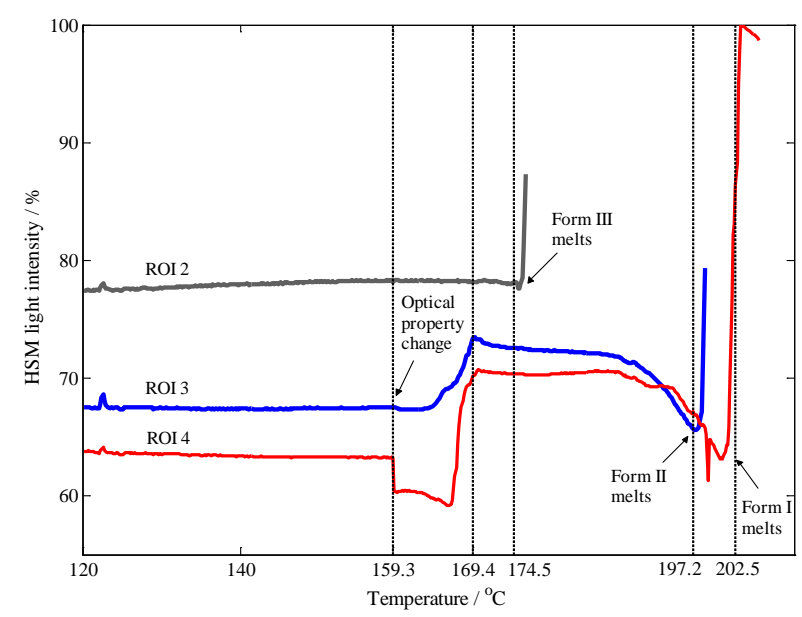

Figure 8. HSM light intensity profiles of sulfathiazole crystals obtained by method 2 at three different ROIs; a crystal that melts at $174.5^{\circ} \mathrm{C}$ (ROI 2); crystals that melt at $197.2^{\circ} \mathrm{C}$ (ROI 3) and a crystal that melts at $202.5^{\circ} \mathrm{C}$ (ROI 4).

\subsection{Crystals obtained by method 3 .}

The obtained DSC thermogram and the HSM light intensity for the sulfathiazole crystals from method 3 are presented in Figure 9. Three endotherm peaks were shown by the DSC thermogram. The first peak had a maximum of $121^{\circ} \mathrm{C}$, the second at $162^{\circ} \mathrm{C}$ and the third at $203.5^{\circ} \mathrm{C}$. The third peak corresponds to the melting peak of form I. The formation of the second peak is in agreement with the observation by previous researchers [28], who deduced that form III transforms into form I in the temperature range of 150 to $170^{\circ} \mathrm{C}$ without showing any melting (of form III at $175^{\circ} \mathrm{C}$ ). This polymorphic transformation event implied by the results of the DSC analysis was confirmed by the HSM analysis. No melting, but a change in optical property of the crystals, was observed as shown by the difference between the highlighted crystals in (a) and (b) in Figure 10. The formation of the first peak may correspond to the polymorphic transformation of form II to form I as observed in section 3.1. This indicates that form II crystals may be present initially, together with form III 
crystals. However, the HSM analysis shows that form II crystals were not transformed to form I since no change in the light intensity profile was detected by the HSM at $121^{\circ} \mathrm{C}$; instead the HSM analysis shows the presence of a crystal that melted at the melting temperature of form II $\left(197.5^{\circ} \mathrm{C}\right)$, as shown by the highlighted region ROI 2 in Figure 10(c) and indicated by a slight fluctuation of the HSM light intensity profile at that temperature in Figure 9. The findings from both characterisation techniques, therefore, lead to the same conclusion that form II crystals were present in the sample. Besides that, the HSM analysis result implies that form II exists as traces and it was only by chance that one of them appeared in the sample during analysis. This in turn signifies a setback of microscopy techniques in which the quality of their results is highly dependent on the quality of the sample due to the fact that only a small number of crystals appear in the interrogation window. The HSM light intensity profile of all crystals in the frame (ROI 1) presented in Figure 9 shows that the responses to the thermal events that occurred below $170^{\circ} \mathrm{C}$ were slightly disturbed by noise caused by the slight movement of some of the crystals, which has been observed to occur during heating. It is reported that besides an optical property change, a polymorphic transformation may also result in a movement of crystals since the transformation events may be accompanied by a change in volume of the crystals [39]. This observation demonstrates a limitation of the HSM light intensity profile in that it can be very sensitive to noise due to crystal movements.

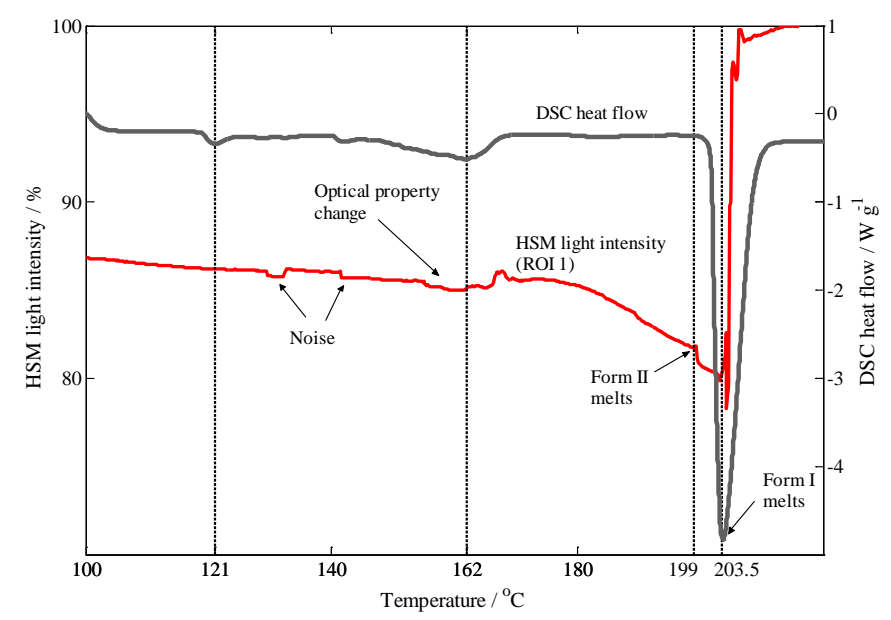

Figure 9. DSC thermogram and HSM light intensity of sulfathiazole crystals obtained by method 3. 

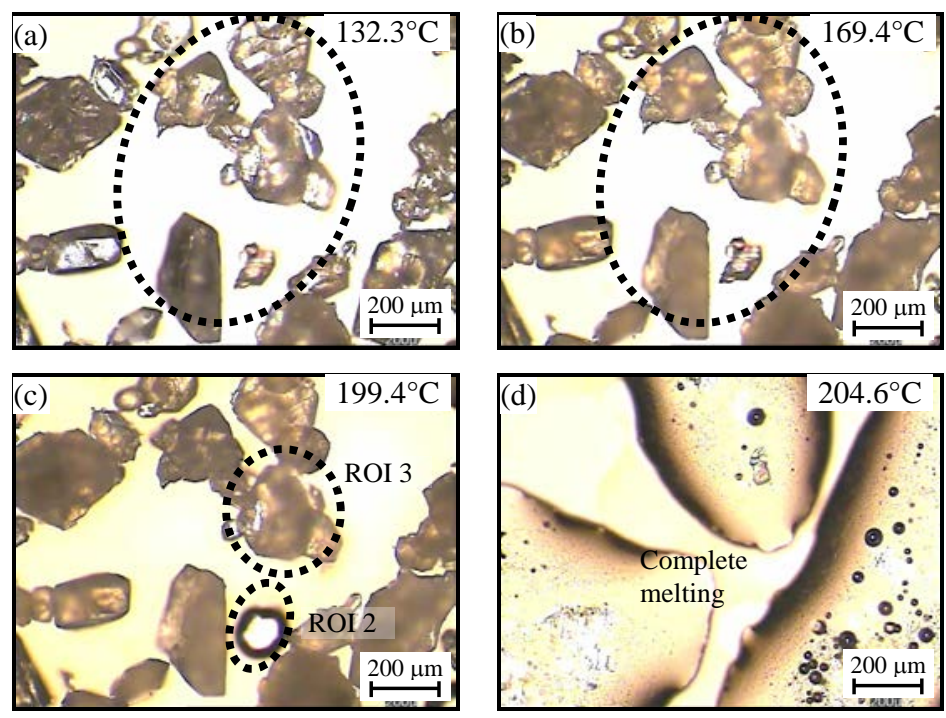

Figure 10. Images of sulfathiazole crystals obtained by method 3 during HSM analysis taken at (a) $132.3^{\circ} \mathrm{C}$; (b) $169.4^{\circ} \mathrm{C}$; (c) $199.4^{\circ} \mathrm{C}$; and (d) $204.6^{\circ} \mathrm{C}$.

Figure 11 compares the HSM light intensity profiles computed from three different ROIs: all crystals on the frame (ROI 1), a crystal that melts at $199^{\circ} \mathrm{C}$ (ROI 2) and a crystal that melts at $203.5^{\circ} \mathrm{C}$ (ROI 3). As was expected, ROI 2 does not show any light intensity change at $121^{\circ} \mathrm{C}$ as detected by the DSC since the crystal should not undergo polymorphic transformation. Besides showing a sharp increase in the light intensity due to melting at $197.5^{\circ} \mathrm{C}$, ROI 2 also shows a sharp increase in the light intensity at $170.8^{\circ} \mathrm{C}$, which corresponds to a change in the crystal's optical property. This result implies that the change in optical property may not necessarily be due to the polymorphic transformation, but could also be due to a change in the surface property of the crystals due to the effect of increasing temperature. ROI 3, on the other hand, shows an increase in the light intensity profile at $165^{\circ} \mathrm{C}$, which is $5.8^{\circ} \mathrm{C}$ lower than in ROI 2 but within the temperature range for transformation of form III to form I crystals $\left(150-170^{\circ} \mathrm{C}\right)$ reported in the literature [28]. It is therefore possible that the sharp increase in the HSM light intensity for ROI 2 and ROI 3 at $170.8^{\circ} \mathrm{C}$ and $165^{\circ} \mathrm{C}$, respectively, was caused by two different events. ROI 3 also shows a change in the HSM light intensity due to melting at $203.5^{\circ} \mathrm{C}$, but the change shows a sharp decrease instead of a sharp increase. This peculiarity may be due to the presence of shadow, which darkens the selected region. However in this case, only the change of the profile is of interest; the direction of the change is not important. The profiles of ROI 2 and ROI 3 seemed to be smoother compared to the profile of ROI 1. These results demonstrate that the HSM light intensity profile is strongly affected by the ROI sample location; the effect of noise and disturbances to the profile could be minimised through a proper selection of the ROI. The results of DSC and HSM with image analysis indicate that the sulfathiazole crystals obtained by method 3 initially comprised form II and form III crystals. 


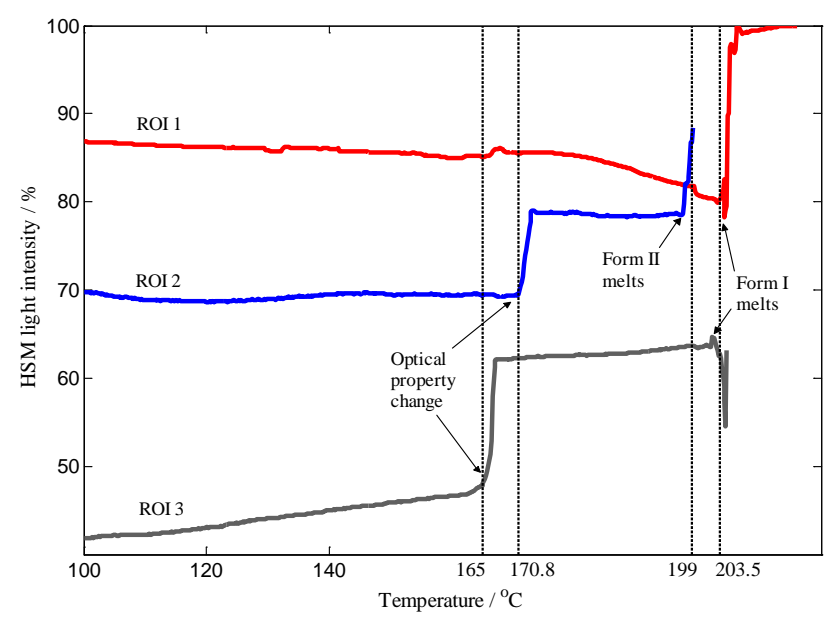

Figure 11. HSM light intensity profiles of sulfathiazole crystals obtained from method 3 at three different ROIs; all crystals on the frame (ROI 1); a crystal that melts at $199^{\circ} \mathrm{C}$ (ROI 2) and a crystal that melts at $203.5^{\circ} \mathrm{C}$ (ROI 3).

\subsection{Crystals obtained by method 4 .}

The results of the DSC and HSM analyses of the sulfathiazole crystals obtained using method 4 are presented in Figure 12. Some images of the crystals during HSM analysis are shown in Figure 13. The DSC thermogram indicates the presence of two endotherm peaks. The first peak maximum occurs at $142.5^{\circ} \mathrm{C}$ whereas the second peak maximum occurs at $203^{\circ} \mathrm{C}$. The trend of the thermogram is in accordance with the results obtained by previous researchers $[3,28]$, in which the first peak was said to be due to the transformation of form IV into form I, whereas the second peak indicated the melting of form I. The HSM analysis confirmed that the first peak was not a melting peak since no melting was observed between $100^{\circ} \mathrm{C}$ and $149^{\circ} \mathrm{C}$, as indicated by the images of the crystals in Figure 13 (a) and (b). There was however a change in the crystals' optical property as clearly shown by the difference in brightness of the highlighted crystals between Figure 13 (a) and (b). The HSM light intensity profile presented in Figure 12 shows a decrease from $140^{\circ} \mathrm{C}$ upwards until it stabilised above $150^{\circ} \mathrm{C}$. A slow decrease of light intensity value is shown from $180^{\circ} \mathrm{C}$ until suddenly the value increased very fast, starting from a temperature that corresponds to the melting of form I. The result signifies the capability of the light intensity profile to identify the beginning of the melting event earlier, since it is very sensitive to the changes happening on the surface of the crystals. The HSM analysis was able to detect a crystal that melts at $175.1^{\circ} \mathrm{C}$ as shown by the highlighted crystal in Figure 13(c). It was not detected by either the DSC analysis or the HSM light intensity profile computed from all crystals in the frame (ROI 1) presented in Figure 12. 


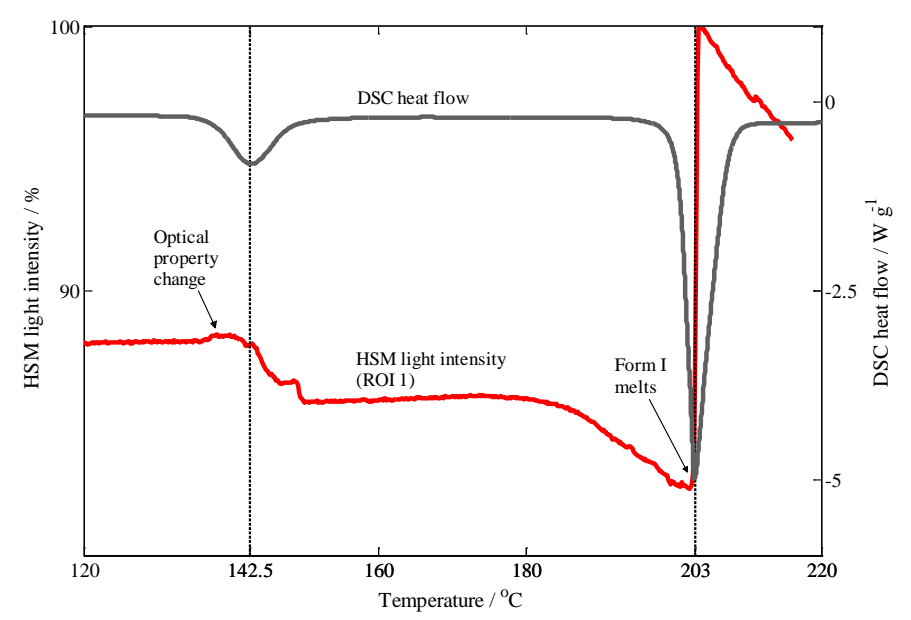

Figure 12. DSC thermogram and HSM light intensity of sulfathiazole crystals obtained by method 4.
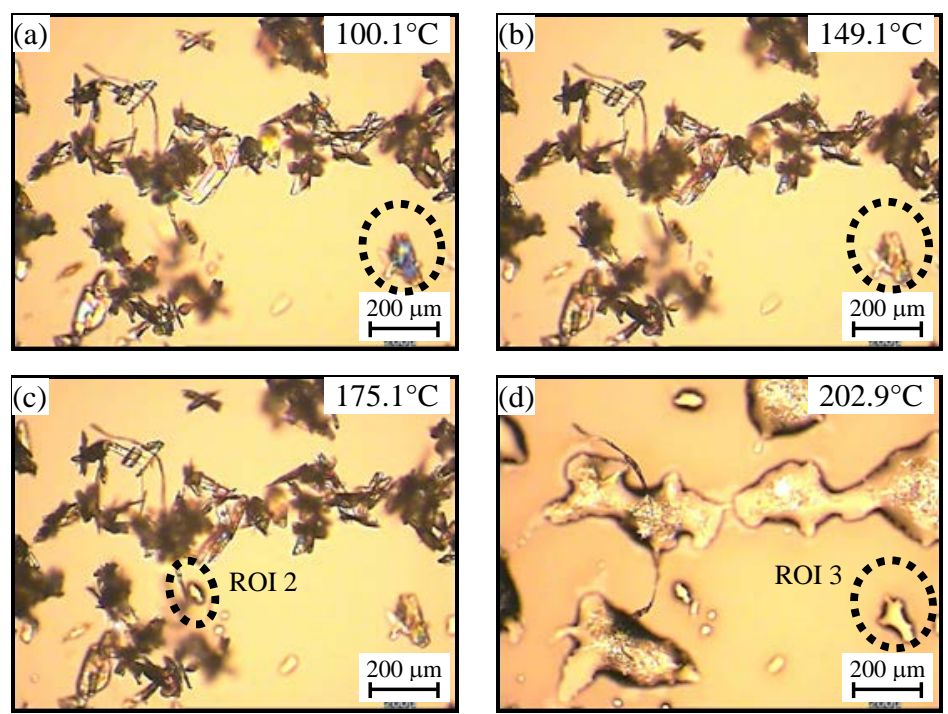

Figure 13. Images of sulfathiazole crystals obtained by method 4 during HSM analysis taken at (a) $100.1^{\circ} \mathrm{C}$; (b) $149.1^{\circ} \mathrm{C}$; (c) $175.1^{\circ} \mathrm{C}$; and (d) $202.9^{\circ} \mathrm{C}$.

Figure 14 shows the HSM light intensity profiles computed from three different ROIs: all crystals on the frame (ROI 1); a crystal that melts at $175.1^{\circ} \mathrm{C}$ (ROI 2), which is highlighted in Figure 13 (c) and a crystal that melts at $203^{\circ} \mathrm{C}$ (ROI 3), which is highlighted in Figure 13 (d). Generally, ROI 3 and ROI 1 are similar in the pattern of their profiles. This implies that most of the crystals in the sample had similar properties to the selected crystal in ROI 3. The profile of ROI 2 displays a sharp increase from $175.1^{\circ} \mathrm{C}$ that corresponds to the melting of the crystal of form III. It also displays a slight fluctuation between $140^{\circ} \mathrm{C}$ to $145^{\circ} \mathrm{C}$, but no significant decrease in light intensity was observed, which indicates the crystal did not undergo a polymorphic transformation. Despite its sensitivity to noise, the results illustrate the capability of the HSM light intensity to describe the thermal events of an individual crystal. The results of DSC and HSM with image analysis show that 
the sulfathiazole crystals obtained by method 4 initially contain crystals of form IV and a trace amount of form III.

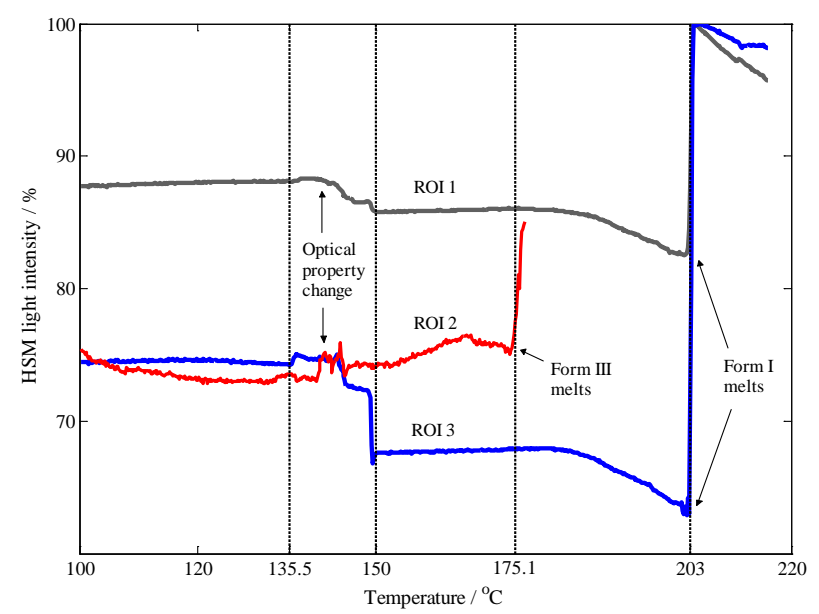

Figure 14. HSM light intensity profiles of sulfathiazole crystals obtained by method 4 at three different ROIs; all crystals on the frame (ROI 1); a crystal that melts at $175.1^{\circ} \mathrm{C}$ (ROI 2) and a crystal that melts at $203^{\circ} \mathrm{C}(\mathrm{ROI} 3)$.

\subsection{Crystals obtained by method 5.}

Figure 15 shows the profiles of the DSC thermogram and the HSM light intensity of the crystals from method 5, while Figure 16 shows the snapshots of the crystals during HSM analysis. The DSC thermogram indicates the presence of three major endotherm peaks. The first peak at a maximum of $161^{\circ} \mathrm{C}$ corresponds to a change in the optical properties of the crystals. This is verified by the HSM analysis as shown by the difference in the brightness of the highlighted crystals between Figure 16 (a) and (b). As mentioned previously, a peak formation in a temperature range of 150 to $170^{\circ} \mathrm{C}$ may be due to a transformation of form III to form I. However, the HSM light intensity profile computed from all the crystals on the frame (ROI 1) presented in Figure 15 does not show any change in optical property of the crystals. This may be due to the averaging-out effect that makes the event undetectable in the HSM light intensity profile. The melting of the crystals at $197^{\circ} \mathrm{C}$ and $203^{\circ} \mathrm{C}$ are illustrated by the HSM light intensity profile in Figure 15 as two consecutive sharp increases. 


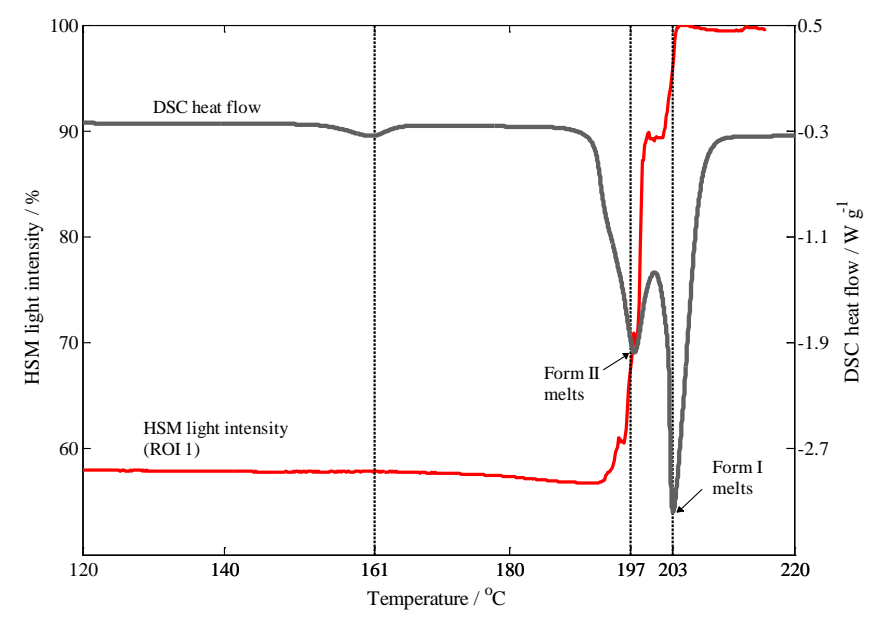

Figure 15. DSC thermogram and HSM light intensity of sulfathiazole crystals obtained by method 5.
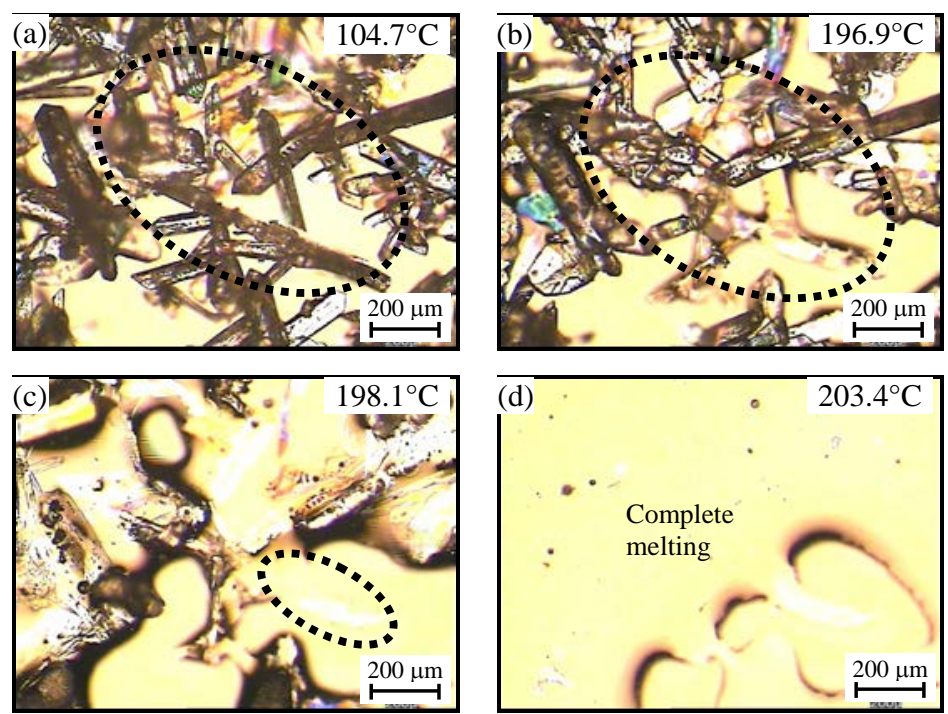

Figure 16. Images of sulfathiazole crystals obtained by method 5 during HSM analysis taken at (a) $104.7^{\circ} \mathrm{C}$; (b) $196.9^{\circ} \mathrm{C}$; (c) $198.1^{\circ} \mathrm{C}$; and (d) $203.4^{\circ} \mathrm{C}$.

Figure 17 compares the HSM light intensity profiles between the one computed from all crystals in the frame (ROI 1) with another from a crystal that melts at $197^{\circ} \mathrm{C}$ (ROI 2) as highlighted in Figure 16 (c). The HSM light intensity profile of ROI 2 differentiates itself from the profile of ROI 1 by not indicating melting at $203^{\circ} \mathrm{C}$. The results signify the potential of the HSM light intensity profile to provide a unique description of the changes happening to individual crystals. The results of a combined approach of DSC and HSM with image analysis show that the sulfathiazole crystals obtained by method 5 initially contain crystals of form II and form III. 


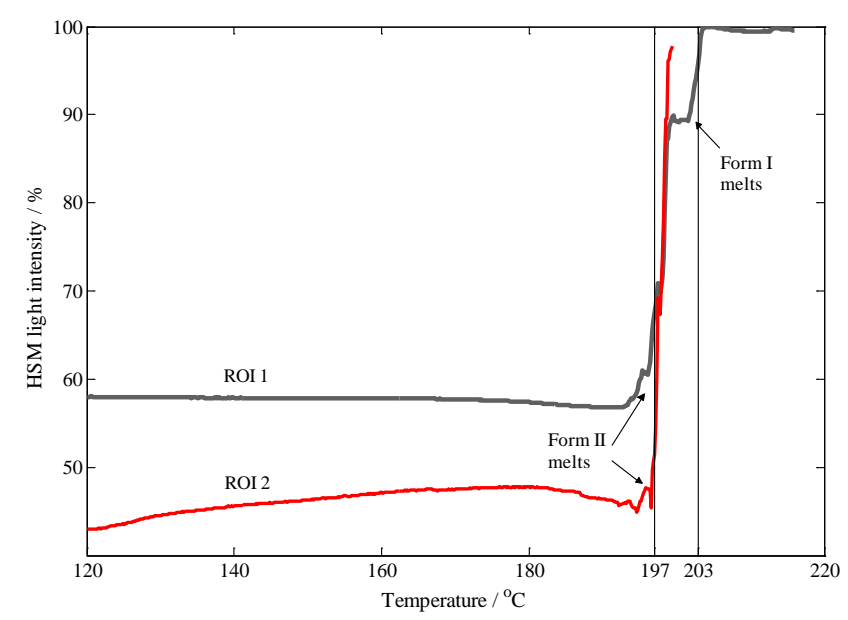

Figure 17. HSM light intensity profiles of sulfathiazole crystals obtained by method 5 at three different ROIs; all crystals on the frame (ROI 1); a crystal that melts at $197^{\circ} \mathrm{C}$ (ROI 2) and a crystal that melts at $203^{\circ} \mathrm{C}$ (ROI 3).

\section{Conclusions}

The crystallization of sulfathiazole polymorphs was investigated by a combined DSC-HSM with image analysis approach. The approach provides synergistic benefits of two characterisation techniques and the use of image analysis gives a unique insight into the thermal behaviour of the polymorphic system. The capability of the HSM image analysis to provide alternative and quantitative ways of presenting the HSM results has been demonstrated. Despite its sensitivity to noise, the light intensity profile obtained from HSM image analysis was found to be capable of describing thermal behaviour of individual crystals and its sensitivity to the changes happening on the surface of these crystals allowed verification of thermal events. The results of the experiments showed that, although the methods to produce pure polymorphs were used, most of the time sulfathiazole crystallized as mixtures of polymorphs.

\section{References}

1. Karpinski, P. H., Chem. Eng. Technol., 2006, 29 (2), 233 - 237.

2. Hilfiker, R.; Blatter, F.; von Raumer, M., Relevance of solid-state properties for pharmaceutical products, in: Polymorphism in the pharmaceutical industry, Hilfiker, R. (ed.), Wiley-VCH Verlag GmbH \& Co., 2006, 1 - 18.

3. Kordikowski, A., Shekunov, T., York, P., Pharm. Res., 2001, 18(5), 682 - 688. 
4. Pollanen, K.; Hakkinen, A.W.; Reinikainen, S.P.; Louhi-Kultanen, A.; Nystrom, L., Chem. Eng. Res. Des., 2006, 84, 47-59.

5. Craig, D.Q.M. \& Reading, M. (ed.), Thermal analysis of pharmaceuticals, CRC Press, 2007.

6. Barnes, A. F.; Hardy, M. J.; Lever, T. J., J. Therm. Anal., 1993, 40, 499-509.

7. Giron, D., J. Pharm. Biomed. Anal. 1986, 4, 755-770.

8. Giron, D., Thermochimica Acta, 1995, 248, 1-59.

9. Giron, D., PSTT, 1998, 1(5), 191-199.

10. Reading, M., Craig, D.Q.M., Principles of differential scanning calorimetry, in: Thermal analysis of pharmaceuticals, Craig, D.Q.M. \& Reading, M. (ed.), CRC Press, 2007, 1-20.

11. Clas, S.-D.; Dalton, C. R.; Hancock, B. C., PSTT, 2(8), 311-320.

12. Vitez, I.M., Newman, A.W., Davidovich, M., Kiesnowski, C., Thermochimica Acta, 1998, 324, 187-196.

13. Marthi, K.; Ács, M.; Pokol, G.; Tomor, K.; Eröss-Kiss, K., J. Thermal Anal., 1992, 38, 10171025.

14. Vitez, I. M.; Newman, A.W., Thermal microscopy, in: Thermal analysis of pharmaceuticals, Craig, D.Q.M. \& Reading, M. (ed.), CRC Press, 2007, 221-264.

15. Patience, D. B.; Dell'Orco, P. C.; and Rawlings, J. B., Org. Proc. Res. Dev., 2004, 8 (4), 609615.

16. Calderon De Anda, J.; Wang, X. Z.; and Roberts, K. J., Chem. Eng. Sci. 2005, 60, 1053-1065.

17. Wang, X. Z.; Roberts, K. J.; and Ma, C., Chem. Eng. Sci., 2008, 63, 1173-1184.

18. Giron, D., J. Therm. Anal. Cal., 2001, 64, 37-60. 
19. Giron, D., J. Therm. Anal. Cal., 2002, 68, 335-357.

20. Pommerenke, K., Am. Lab., 2000, 32, 30-32.

21. Richardson, M. F.; Yang, Q.-C.; Novotny-Bregger, E.; Dunitz, J. D., Acta Cryst. (1990). B46, 653-660.

22. Wiedemann, H. G.; Bayer, G., J. Thermal Anal., 1985, 30, 1273-1281.

23. Wiedemann, H. G.; Felder-Casagrande, S., Thermomicroscopy, in: Handbook of thermal analysis and calorimetry. Vol. 1: Principles and practice, Brown, M. E. (ed.), Elsevier Science B. V., 1998, 473-496.

24. Apperley, D.C., Fletton, R.A., Harris, R.K., Lancaster, R.W., Tavener, S., Threlfall, T.L., J. Pharm. Sci., 1999, 88(12)

25. Chan, F. C.; Anwar, J.; Cernik, R.; Barnes, P.; Wilson, R. M., J. Appl. Cryst., 1999, 32, 436441.

26. Hughes, D. S.; Hursthouse, M. B.; Threlfall, T.; Tavener, S., Acta Cryst. C, 1999, 55, 18311833.

27. Blagden, N., Davey, R. J., Lieberman, H. F., Williams, L., Payne, R., Roberts, R., Rowe, R., Docherty, R., J. Chem. Soc., Faraday Trans., 1998, 94(8), 1035-1044.

28. Anwar, J.; Tarling, S.E.; Barnes, P., J. Pharm. Sci., 1989, 78 (4), 337-342.

29. Lagas, M., Lerk, C.F., Int. J. Pharm., 1981, 8, 25-33.

30. Mesley, R., J. Pharm. Pharmacol., 1971, 23, 687-694.

31. Hughes, D. S.; Hursthouse, M.B.; Lancaster, R.W.; Tavener, S.; Threlfall, T.; Turner, P., 1997. J Pharm Pharmacol 49: 20.

32. Anderson, J.E.; Moore, S.; Tarczynski, F.; Walker, D., Spectrochimica Acta Part A, 2001, 57(9), 1793-1808. 
33. Aaltonen, J.; Rantanen, J.; Siiria, S.; Karjalainen, M.; Jorgensen, A., Laitinen, N.; Savolainen, M.; Seitavuopio, P.; Louhi-Kultanen, M.; Yliruusi, J., Anal. Chem., 2003, 75, 5267-5273.

34. Hakkinen, A.; Pollanen, K.; Karjalainen, M.; Rantanen, J.; Louhi-Kultanen, M.; Nystrom, L., Biotechnol. Appl. Biochem., 2005, 41, 17-28.

35. Gelbrich, T.; Hughes, D. S.; Hursthouse M. B.; Threlfall, T. L., CrystEngComm, 2008, 10, 1328-1334.

36. Lever, T., Optimizing DSC experiments, in: Thermal analysis of pharmaceuticals, Craig, D.Q.M. \& Reading, M. (ed.), CRC Press, 2007, 24-51.

37. Urakami, K., Shono, Y., Higashi, A., Umemoto, K, Godo, M., Bull. Chem. Soc. Jpn., 2002, 75, 1241-1245.

38. Miller, R. P.; Sommer, G., J. Sci. Instrum., 1966, 43, 293-297.

39. Warrington, S. B., Simultaneous thermal analysis techniques, in: Principles of thermal analysis and calorimetry, Haines, P. J. (ed.), The Royal Society of Chemistry, 2002, 166-189.

\section{Acknowledgement}

Financial support provided by the Engineering and Physical Sciences Research Council (EPSRC), U.K., (grant EP/E022294/1) is gratefully acknowledged. One of the authors (MRAB) is grateful to the Malaysian Ministry of Higher Education for a scholarship. 